\title{
Biogeochemical variability controls heavy metal mobility within alluvial aquifers
}

MAYA ENGEL ${ }^{1}$, KRISTIN E. BOYE ${ }^{2}$, VINCENT NOEL ${ }^{2}$, JOHN R. BARGAR ${ }^{2}$ AND SCOTT FENDORF ${ }^{1}$

${ }^{1}$ Department of Earth System Science, Stanford University, Stanford, CA, USA

${ }^{2}$ Stanford Synchrotron Radiation LightSource, SLAC National Accelerator Laboratory, Menlo Park, CA, USA

Alluvial aquifers instore the majority of groundwater resources for communities globally. Though composed mainly of sand and gravel, fine-grained lenses of clay and organic matter, enriched in iron and sulfur, embedded within the aquifer sand create a rich and heterogeneous redox environment. Variation in redox conditions have strong influences on biogeochemical cycling, heavy metal behaviour and resulting groundwater quality.

The ultimate impact of spatially and temporally heterogeneous redox conditions on heavy metal fate in complex groundwater systems such as alluvial aquifers remains largely unresolved. Therefore, we examined the mobility and speciation of $\mathrm{Zn}$ and $\mathrm{Ni}$ in a dual-domain column containing two fine-grained sediment lenses surrounded by coarse sand. The columns were fed with aerated groundwater containing dissolved $\mathrm{Zn}$ and $\mathrm{Ni}$, where half of the columns were supplemeted with nitrate.

The lenses promoted reducing conditions in the sand in spite of the flow of oxygenated groundwater. This was evidenced by the presence of ferrous iron in the sand succeeding the lenses as well as the appearance of nitrite in columns supplemented with nitrate.

Though dissolved $\mathrm{Zn}$ and Ni were mostly undetectable in the lenses throughout the experiement, final retained amounts of $\mathrm{Zn}$ and Ni were 2-fold higher in the lenses compared to the sand. This implies that metal sorption was more appreciable in the fine-grained lenses. Incorporation of $\mathrm{Zn}$ and $\mathrm{Ni}$ into sulphide minerals appears to be the dominant retention mechanism, resulting in removal of dissolved sulphide in the lenses upon $\mathrm{Zn}$ and $\mathrm{Ni}$ introduction; S-XANES data reveals the presence of mackinawite in the lenses.

Solid phase chemical extractions illustrated more $\mathrm{Ni}$ remained in the non-extractable pool in comparison to $\mathrm{Zn}$, suggesting differences in the binding of the two metals. Zn, $\mathrm{Ni}$ and Fe EXAFS and Mossbauer spectroscopy will help to decipher the differences between the two metals. Our findings show that a varying redox environment may have profound influences on the biogeochemcial processes influencing heavy metal mobility in simulated alluvial aquifers. 